\title{
Learning Outcome-Based Teaching of Power Electronics and Electric Machines Hybrid Laboratory Using ABAL Method
}

\author{
M Umair Safder ${ }^{1}$ (umairsafder@ @uilahore.edu.pk), \\ Yaqoob Javed ${ }^{1}$ (yaqoob.javed@ cuilahore.edu.pk), \\ Subhan Khan1(Subhankhan@cuilahore.edu.pk), \\ Mujtaba Hussain Jeffery¹(m.jaffery@cuilahore.edu.pk), \\ Noman Naeem ${ }^{1}$ (noman.naeem@cuilahore.edu.pk) \\ ${ }^{1}$ Department of Electrical Engineering, COMSATS University Islamabad, Lahore \\ Campus, Pakistan
}

\begin{abstract}
This article discusses an ABAL technique for teaching Power Electronics (PE) and Electric Machines (EM) as a hybrid laboratory course for undergraduate students to develop and execute real-world engineering challenges. ABAL is a form of active learning that is a subset of learner-centered instruction (LCT). The DC/DC converter, in conjunction with the DC speed control, stimulates the motor independently. Additionally, a DC/AC converter is used to regulate the rotational speed of an induction motor. The results are then explored using the ABAL experimental approach on a hardware platform. Additionally, this study addresses issue identification, equipment selection, circuit design, hardware mounting, and critical examination of the hybrid laboratory's outcomes. The ABAL technique was evaluated on the basis of student happiness, feedback, grades, and motivation to solve real-world problems rather than memorising engineering principles and completing so-called lab routines and tasks.
\end{abstract}

Keywords: Application Based Active Learning, Active Learning Methodology, Cooperative Learning, DC/DC converter, DC motor, DC/AC converter Engineering Education, Learnercentered teaching.

\section{Introduction}

In tertiary education, technical subjects are frequently founded on learner-centered instruction (LCL). It is subdivided into active learning methodologies (ACM), cooperative learning methodologies (CL), inductive teaching methodologies (IT), and project-based learning methodologies. Students are encouraged to work independently on a real-world problem under the guidance of an instructor in the ACM. On the other hand, CL requires groups of students to collaborate in order to answer assigned issues. Whereas IT is the conventional method of teaching in which a debate is taken from broad to detailed. The primary objective of any university is for its undergraduate students to build similar approaches utilising their technical skills, rather than to study or imitate already existing techniques.

Various teaching strategies have certain limitations on student learning since they do not require students to apply their technical knowledge to a real-world situation. They like to operate under the guidance of a project handbook [1]. Additionally, due to budget constraints, the majority of colleges advocate simulation-based solutions to real-world problems. However, this phase of learning does not address the practicality of any technological challenge [2]. The converters (DC- 
DC, DC-AC, AC-AC, and AC-DC) are one of the course materials covered by any university in the PE module [1]-[3].

The teacher explains the fundamental theoretical principles of the converter and solves numerical problems relating to the converter in the theory class. While in the laboratory, students use a PE instructional trainer and simulation software to verify the converters' reaction [2]. However, this style of instruction is qualitatively insufficient. Additionally, this course may be challenging for students to complete. Additionally, their academic performance deteriorates over time. The EM module covers topics such as DC and AC machines, motors, and transformers. The course's aims are to familiarise students with motor characteristics, operating principles, and speed control techniques. Despite the rich information, pupils are unable to create a converter to regulate the speed of motors owing to module switching. One explanation for this drastic behaviour is a failure to revise fundamental notions [4]-[6]. The primary objective of this suggested technique is to enhance their educational capacities and contentment.

Three challenges plague the teaching of the PE module: poor passing rates, students who linger on their work until exams, and students who lose interest in the subject. As a result, a novel ABAL-based learning approach is developed and deployed to address these issues. Additionally, this article discusses a hardware-based ABAL technique for teaching a PE/EM hybrid laboratory course at the University of Central Punjab (UCP) in Lahore, Pakistan. Finally, the suggested technique's robustness is determined by the students' performance, grades, and comments. The following are the desired outcomes of this proposed methodology:

- To improve the technical understanding of the undergraduate students in the PE and EM modules.

- To engage students in different activities throughout the semester using learning material.

- To effectively reduce cramming and improve self-learning.

- To enhance students' exposure in the domain of engineering education.

Numerous research have been published on the use of various teaching methods, most notably PBL, in the creation of the electrical engineering curriculum, which covers circuits, electronics, signal processing, communications, microprocessors, and embedded systems [1]-[8]. Numerous writers have adapted the PBL technique in order to demonstrate its efficacy at a variety of institutions across the world [5]-[8]. PBL is active learning that coexists alongside lecture-based instruction in areas such as power, energy, and control systems [9]-[14], where students gravitate towards group-based learning and project management. Some of these studies used a pure PBL approach, which focuses on purely engaged learning by assigning students to work in small groups on a specific problem from a single course [3], while others used a hybrid PBL approach, in which PBL was modified and a hybrid course problem was assigned to a group of students to propose a solution [4].

Additionally, some researches use single- or multiple-module PBL [5] or PBL [15]. PBL has been shown to increase student grades in several studies [16]-[20]. Certain academics opt not to publish grade increases [7]. The group study might be one explanation for this, since students did 
not have the opportunity to use their individual abilities to comprehend the technical problem and offer a solution, which could then be discussed with another student. Numerous approaches are being used in various nations to facilitate good engineering education, and researchers and teachers are reviewing them.

These approaches were validated through comparisons to traditional teaching and student surveys. Several significant approaches are described in this section. Cooperative learning is optimal for developing the theoretical foundations of any subject. Assigned work is distributed among group members, since CL students are encouraged to work collaboratively. Within each group, each student is assigned a task that requires him or her to collaborate with students from other groups who have the same assignment in order to become an expert on the subject. The members of the group are expected to return to their basic groups as experts in their given duties or themes, and they are responsible for educating other students from diverse groups about their competence. As a result, the group must be capable of applying the acquired information to the exam or problem statement [21].

CL methods encompass a broader range of practises in engineering education, of which PBL is one [22]. Students are separated into groups and assigned assignments based on their learning method [23]. The assigned projects may be multidisciplinary in nature rather than focusing only on the study field. Furthermore, PBL enables group members to gain broad wine competencies including as teamwork, autonomous learning, general understanding of technology, troubleshooting, information management, and social and presentation skills [24], [25]. A guidance on task planning, development, and evaluation may be found in [26]. [26] discusses the rationale for utilising PBL, the findings of PBL inquiries, and other elements of its application. Examples of using PBL, as well as related issues, can be found in research papers that are dainty: the coordination of a large number of subjects using PBL [27], strategies for increasing motivation and acquisition of generic wine skills, and the benefits and drawbacks observed by students and teachers when using PBL.

Active learning includes students directly and actively participates them in the learning process. Students are involved in all aspects of the planning, design, implementation, and assessment of education. Benefits and Suggested Strategies, the emphasis is on the learner and his or her ability to retain material while expressing science at a higher level of thinking, teamwork, motivation, and a range of learning styles. Learners are participating in goal-oriented tasks, and rather than being directive, the instructor performs less than $50 \%$ of the talking and no more than $75 \%$ of the decision-making good degree feedback from teacher and student [21]. Students are exposed to a variety of problem-solving techniques that make producing answers less overwhelming; in groups, individuals can resign but are more likely to stay; and students learn best what teachers teach.

This research suggested a solution to engineering education by introducing an effective strategy known as the ABAL method, which significantly improves students' learning outcomes. Rather to focusing on a single course at a time, the ABAL approach connects two or more courses together to tackle a specific problem. For instance, a student would spend a semester studying 
electrical machines before moving on to a power electronics course. Thus, when studying power electronics, we created a real-world challenge that incorporates concepts from the power electronics and electric machine courses.

The following sections comprise the paper: Section 2 discusses the ABAL technique for power electronics. Sections 3 and 4 cover the ABAL's student assessment standards and conclusions. Finally, section 5 summarises the paper and discusses possible next directions.

\section{ABAL methodology for hybrid laboratory}

As previously stated, the ABAL technique is entirely built on active learning. to construct a challenge while keeping the teaching methods in mind, students were assigned a variety of realworld situations in addition to their regularly assigned lab activities. The two challenges were derived from a local industry in which two different types of motors, AC and DC, are subjected to speed regulation utilising simple fundamental procedures rather than sophisticated current equipment and processes. On an original premise, it was a four-week lab session. two weeks for a single real-world problem that will encompass identification, equipment selection, design, and hardware product development with satisfying outcomes. as in this strategy, each pupil use their expertise to overcome this. Two challenges are presented and addressed in length in the following sections, together with their specifics, design, and projected solutions.

\subsection{DC/DC converters design for DC motor}

Prior to enrolling in the Power, Electronics course indicated here, the student must first complete prerequisite courses, such as foundations of electronics and electrical machines. These classes employed a methodical approach that included lectures, problems, and science lab practical practise with instructional equipment. The power electronics course covers both DC to DC and DC to AC converters. These were taught by the teacher discussing the theory and working through various issues in class, followed by laboratory sessions in which students worked with an educational converter control panel and simulations platform. This structure was found to be insufficient quantitatively and qualitatively. As a result, their academic performance was subpar, and they struggled conceptually with the course.

As a result, the instructor will assign pupils a real-world challenge that incorporates P.E. and electric machine ideas. Students are encouraged to find the solution path independently and not to be concerned about marks. The issue is derived from a local industry. Although the industry has already developed remedies for that specific issue. However, for a third-year student, this is a novel experience. The students have learned how to control the speed of a DC motor and are currently practising with PE converters; consequently, they have been provided with a hybrid laboratory to test their designs and present solutions rather than working on the educational trainer board during lab sessions throughout the semester. The DC/DC converter and motor requirements for the realtime application are listed in Table 1, together with the converter and motor specifications. Students are encouraged to finish the problem's paper work during the first week of the session and the hardware implementation during the second week. Students may request an extension of the time allotted for the issue if they believe more time was necessary for implementation and troubleshooting. Due to the fact that the ABAL technique is built on active learning and individuality, not all students have the same degree of intelligence or ability to multitask. 


\subsection{DC/DC boost Converter Mounting and connection with DC machine}

After successfully testing of the designed converter a $120 \mathrm{~W}$ DC motor's speed has controlled using the DC/DC converter by varying its duty cycle. Duty cycle is changed using function generator. All the equipment used by students are available in this hybrid laboratory session. CRO is used to analyze the waveforms along with multimeters to keep an eye of voltage and current changes. Training panel is used for supply and measurements as shown in fig 1 . The designed parameters of the converter are shown in table 2 in which students designed the very essential parameters and then selected the appropriate components from the lab for hardware implementation. they use series parallel combination of available capacitors and inductors to make equivalent value as close to calculated value as possible.

\begin{tabular}{|c|c|}
\hline Maximum input voltage & $100 \mathrm{~V}$ \\
\hline Maximum output voltage & $110 \mathrm{~V}$ \\
\hline Maximum output current & $1.3 \mathrm{~A}$ \\
\hline Allowable max load current & $1.35 \mathrm{~A}$ \\
\hline Allowable max load voltage & $115 \mathrm{~V}$ \\
\hline Deviation in voltage & $0.5 \%$ \\
\hline Deviation in current & $10 \%$ \\
\hline Motor Rated Voltage & $110 \mathrm{~V}$ \\
\hline Motor Rated Current & $1.25 \mathrm{~A}$ \\
\hline Motor Rated speed & $1000 \mathrm{RPM}$ \\
\hline Motor Rated power & $120 \mathrm{~W}$ \\
\hline
\end{tabular}

Table 1: DC/DC converter and motor requirement for the real-time application

After implanting on hardware, they test it without motor and after that attached appropriate motor to the converter to finally control its speed. The final results in term of speed control is given in table 3.in which you can see the variation of speed with duty cycle. The most satisfactory thing in this ABAL methodology is that students have no burden of grades and they are free to use anything they want to complete their task. They word very enthusiastically in lab to make more efficient and straightforward design by using their very own gained knowledge about the power electronics and electrical machine.

\begin{tabular}{|c|c|}
\hline Inductor & $0.96 \mathrm{mH}$ \\
\hline Input capacitor & $0.68 \mathrm{uF}$ \\
\hline Output capacitor & $0.8 \mathrm{uF}$ \\
\hline Switching frequency & 30 to $60 \mathrm{KHz}$ \\
\hline Duty cycle & $10 \%$ \\
\hline MOSFET & IRF 740 \\
\hline
\end{tabular}

Table 2: SAMPLE STUDENT Designed parameters of the DC/DC converter 


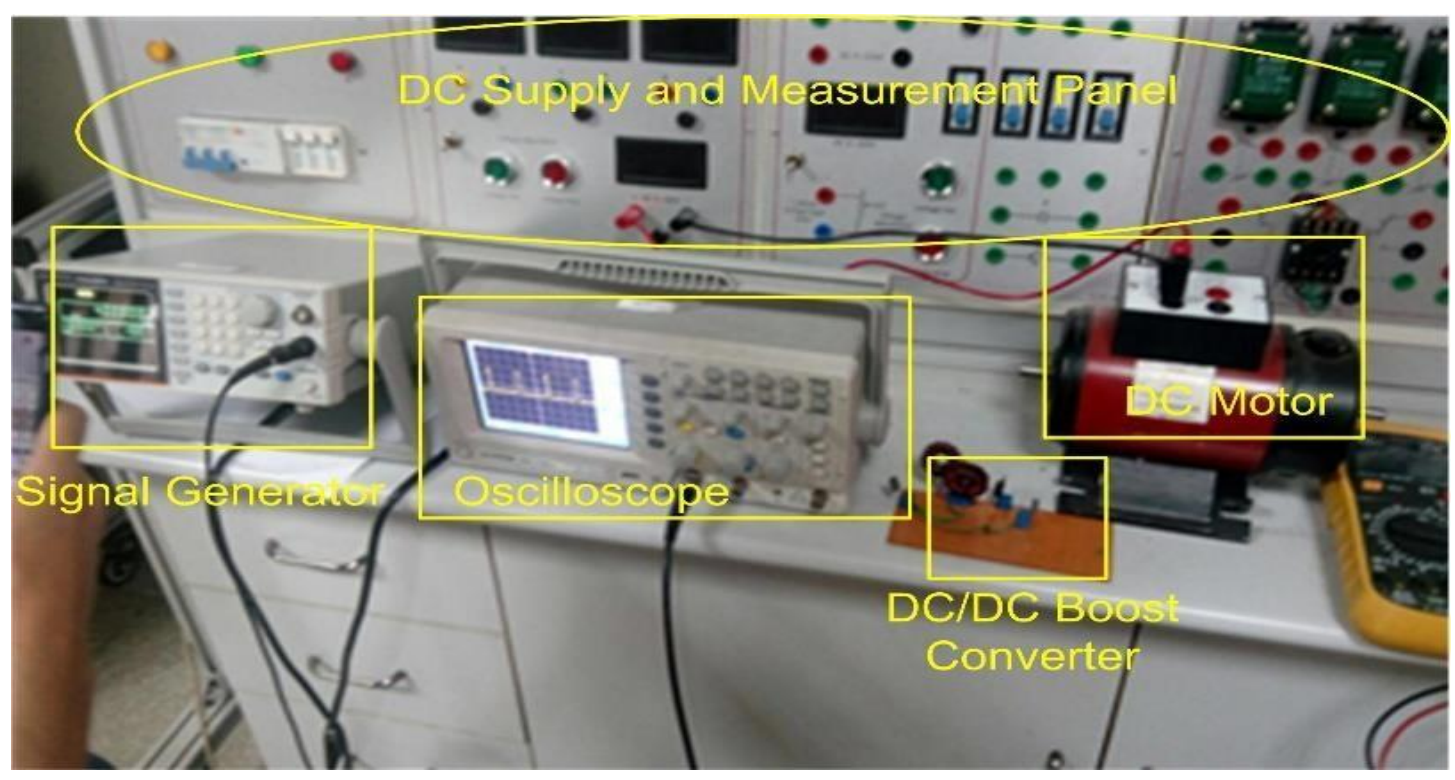

Figure 1: DC/DC converters designed setup for DC motor speed control

\begin{tabular}{|c|c|c|c|}
\hline $\begin{array}{c}\text { Duty cycle } \\
(\%)\end{array}$ & $\begin{array}{c}\text { Converter } \\
\text { input }(\mathrm{Vi})\end{array}$ & $\begin{array}{c}\text { Converter output to } \\
\text { the motor }(\mathrm{Vo})\end{array}$ & $\begin{array}{c}\text { Motor speed } \\
(\text { RPM })\end{array}$ \\
\hline 10 & 37 & 41.2 & 320 \\
\hline 20 & 37 & 48.7 & 351 \\
\hline 30 & 37 & 53.4 & 474 \\
\hline 10 & 100 & 108.6 & 1070 \\
\hline 20 & 100 & 113.3 & 1175 \\
\hline 30 & 100 & Not allowed & Not allowed \\
\hline
\end{tabular}

Table 3: Sample Student Results of the given tasks

\subsection{DC/AC converters hardware design for $\mathrm{AC}$ motor}

One of the major area of power electronics is to study inverter (DC/AC converters), which can supply power to AC machines. The commonly used inverter topologies are; singlephase bridge inverter (SPBI), three-phase bridge inverter (TPBI), half-bridge inverters (HBI) and push- pull inverter (PPI). Moreover, the output voltage and frequency of the inverter in controlled by the transistors switching angles. Finally, the total harmonic distortion (THD) is minimized by using active power filters. So, students should study the behavior of topologies, control and filters used for the inverters. Fig 2 illustrate the basic block diagram of the converter and inverter circuit.

The problem given to the student is to design a dc to ac converter to control AC induction motor speed. The required parameter of DC to AC converter is shown in table 4 in which the rated voltage and speed of the AC motor is given along with the converter input and output is stated. Initially, the design of dc-ac converter was designed by the students theoretically in the $3^{\text {rd }}$ week of the ABAL session. Secondly, in the $4^{\text {th }}$ week of the session the design of the converter was simulated by using MATLAB/Simulink to check the validity of the design and after that, the 
simulation design is implemented on the hardware. Finally, the output of DC/AC converter, is fed to the induction motor, which will work as a variable frequency drive (VFD) to control the speed of the AC induction motor by changing the frequency of the converter output. Furthermore, the robustness of the hardware setup will be checked by comparing the results with simulated design. So, while implementing the whole setup, the students would be able to understand the design and implementation of DC/AC converter or VFD in real time. Lastly, the project report will include all the theoretical calculations and implementation scheme.

\subsection{DC/AC converter results}

The results shown in the table 5 are result of the hardware implemented setup of the DC/AC for induction motor sped control. Student used breadboard to implement the circuit rather used Vero-board or solder board because the change of burnout and short-circuit is high in DC/AC converter, so they preferred the breadboard. After testing converter alone, motor is connected to converter's output and get the results. We can see form the table 5 that results are adjacent to the calculated values. Frequency shown in the table is the frequency which is fed to the motor to control the speed of the motor and switching of the converter is controlled by function generators. All the work is done by the student under the contact supervision of Lab instructor and lab assistants. The response of the student was very satisfactory when they saw their designed circuit in working condition without using modern techniques and modern equipment. They remark about the ABAL session as real learning session they attended so far.

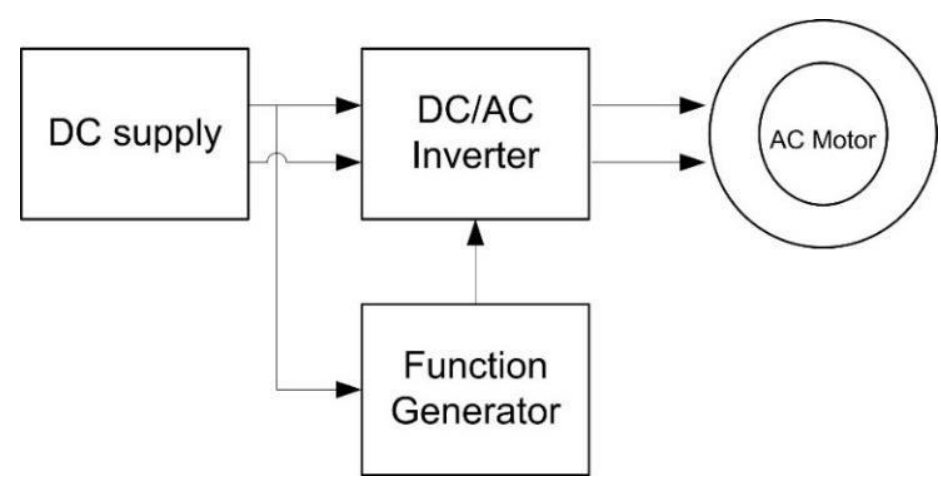

Figure 2: Block diagram of DC/AC converter

\begin{tabular}{|c|c|}
\hline Converter input & $120 \mathrm{DC}$ \\
\hline Converter output & $230 \mathrm{AC}$ \\
\hline motor voltage & 220 \\
\hline Motor power & $120 \mathrm{~W}$ \\
\hline Rated speed & $1500 \mathrm{RPM}$ \\
\hline Motor poles & 4 \\
\hline Rated frequency & $50 \mathrm{~Hz}$ \\
\hline
\end{tabular}

Table 4: DC/AC converter and AC motor parameters.

\begin{tabular}{|c|c|c|c|}
\hline \multicolumn{2}{|c|}{ Calculated results } & \multicolumn{2}{c|}{ Test results } \\
\hline $\begin{array}{c}\text { Freq } \\
(H z)\end{array}$ & $\begin{array}{c}\text { Speed } \\
(R P M)\end{array}$ & $\begin{array}{c}\text { Freq } \\
(H z)\end{array}$ & $\begin{array}{c}\text { Speed } \\
(R P M)\end{array}$ \\
\hline 20 & 600 & 19 & 570 \\
\hline 25 & 750 & 24 & 720 \\
\hline 36 & 1080 & 34 & 1020 \\
\hline 50 & 1500 & 47 & 1410 \\
\hline
\end{tabular}

Table 5: DC/AC converters results 


\section{STUDENT ASSESSMENT}

The laboratory assessment criteria for the students was $25 \%$ for the design, while the hardware implementation marks were $25 \%$ and the final examination weightage will be $50 \%$. Moreover, each laboratory assessment marks are split between regular lab session and ABAL session. $25 \%$ of the design contains a report and a design/implementation performance results. The report contained the designed procedure, simulation and hardware model and final results. Finally, all the assessments are evaluated on the bases of active learning based on ABAL. In the table 6 a student views about the implementation of ABAL session has given. Student are asked some question about this session and some general comments are shown in the said table. The views of student about this lab routine is very satisfactory. Almost $93 \%$ of the total student state the views refereeing to the asked questions rest $7 \%$ just don't answers due to any personal reason but overall, it's showing that young engineering student are interesting in such lab session to developed hands on practice to handle real time problem also these kinds of active learning boost the confident of the students.

\begin{tabular}{|c|c|}
\hline Sample Questions & General comments \\
\hline $\begin{array}{l}\text { what do you think about the methodology of } \\
\text { ABAL lab session? }\end{array}$ & $\begin{array}{l}\text { It's much better than the regular or typical lab } \\
\text { session. In usual lab hours, we are bound to } \\
\text { implement some already solved circuit on the } \\
\text { trainer board. However, in the ABAL session we } \\
\text { have freedom to use our own concepts and any } \\
\text { equipment which is required to solve the given } \\
\text { real time problem. }\end{array}$ \\
\hline Is it a kind of extra burden with regular lab work? & $\begin{array}{l}\text { Well it's a very interesting learning session which } \\
\text { boost our confident about handling real time } \\
\text { problem without any modern tools and internet. } \\
\text { This session is not a burden rather to enhance our } \\
\text { engineering skills. }\end{array}$ \\
\hline $\begin{array}{l}\text { How do you compare this lab session with your } \\
\text { previous semester lab hours? }\end{array}$ & $\begin{array}{l}\text { In our previous years lab session, we have done } \\
\text { lot of pre-defined already solved circuit on trainer } \\
\text { boards or simulation tools, but this session is } \\
\text { much better because we have to think on our own } \\
\text { to figure out the solution without any condition. } \\
\text { The solution can vary from very simple one to } \\
\text { complex depending upon the understanding of the } \\
\text { individual student's knowledge. }\end{array}$ \\
\hline
\end{tabular}

Table 6: Students views about the power electronics and electric machine hybrid lab session using ABAL.

\section{Findings}

This section presents the effects and outcomes of the laboratory sessions. This was assessed by examining the UCP's official evaluation results for student satisfaction, and overall student grades, comparing the academic year 2016-17, before implementation of the ABALbased hybrid laboratory with the academic year 2015-2016, after implementation of the ABALbased hybrid laboratory.

This section presents the results and outcomes of lab sessions. This was concluded by examining the UCP's official assessment results for student satisfaction, and overall student 
grades. Comparison the tutorial year 2016-2017 with implementation of ABAL methodology with the session 2015-2016 without ABAL implementation. The statements on PBL had very good ratings. Students agreed that ABAL results in a more uniform distribution of work throughout the course, makes the course more practical, and increases student interest. They found the project hardware is important for their engineering training and would recommend this form of teaching. The students valued ABAL for developing skills such as the abilities to work effectively as an individual, to apply knowledge in practice, and to communicate with others effectively and confidently. They valued as quite good their development of their abilities to plan their time and to evaluate.

The announcements on ABAL had great appraisals. students concurred that ABAL brings about a more uniform conveyance of work all through the course, makes the course more reasonable, and builds student interest. They found that hardware-based project is vital for their design skills and engineering training and would prescribe this type of teaching. The students esteemed ABAL for creating aptitudes, for example, the capacities to work viably as a person, to apply their gained knowledge in practice and to speak with others adequately and confidently. They valued their development and growth of their abilities to plan their time and to assess.

\subsection{Satisfaction level}

In the academic year 2016-2017, Student's satisfaction level is judged by a survey. The majority student's response regarding laboratory is "Interesting", "well-designed", "Practically implementable" and "easy to implement". Fig 3 show the student response. These results are compared with the student response of the previous session. In both the session same instructor taught the course.

\subsection{Student Grades}

Most grades were in the range of $55-60 \%$ in a certain practical problem before the ABAL because students not provided with hybrid lab and encouragement to use their own skills without internet. After the introduction of ABAL, grades increased to be in the ranges of $70-75 \%$ and 80- $90 \%$ in term of handling the real time problems with a very satisfactory result. Course assessments and methods were the same for these two periods. The higher-grade averages indicate the benefit of the ABAL sessions.

\subsection{Limitations of ABAL}

The outcomes indicated in Sections were found for UCP students between 2016 and 2017 but may not apply to EE module students at different institutions. Nevertheless, it is anticipated that the overall grade and student satisfaction would improve and that their interest would increase to solve the real-world problem. 


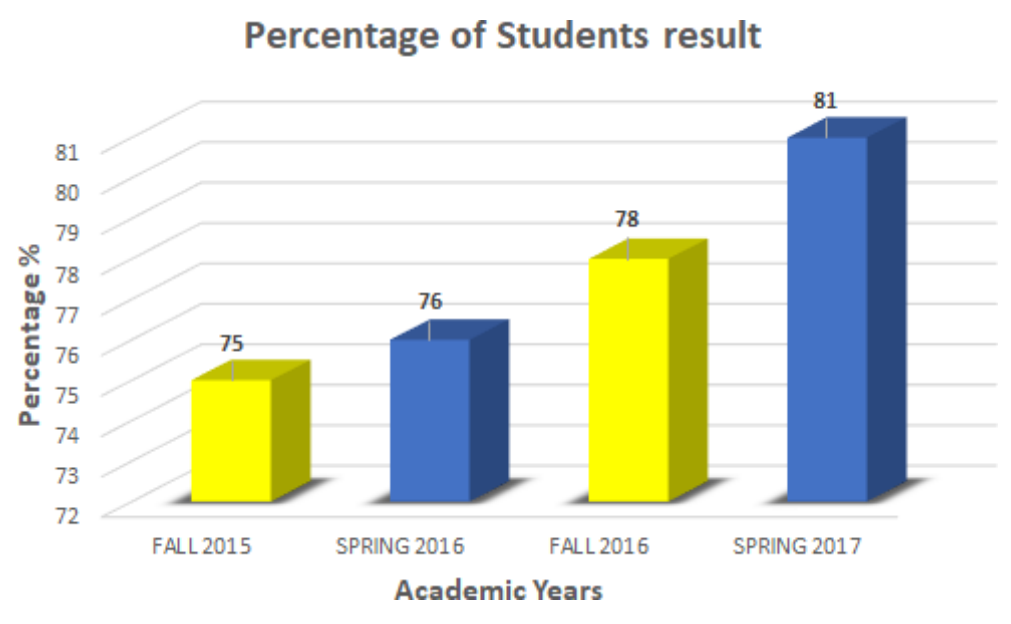

Figure 3 Students grade comparison of the year 2015-2016 and 2016-2017 without and with ABAL respectively

\section{Conclusion}

The purpose of this study is to discuss how to teach the essential ideas of power electronics and electric machines. Under the ABAL lab session, you will design and implement converters for a motor to regulate its speed. Traditional techniques of instruction, such as lectures and report writing, are combined with interactive design-oriented real-world problems. Students work independently to complete their design project, acquiring a firm grasp of the principles, applying their previously acquired engineering knowledge to solve the provided challenge, and obtaining valuable experience with computation and design. Students are primarily driven to study and comprehend the challenge presented in the hybrid laboratory. The pupils' reaction is overwhelmingly good.

\section{References}

[1] F. Shahnia, M. Moghbel, and H. H. Yengejeh, "Motivating Power System Protection Course Students by Practical and Computer-Based Activities," IEEE Trans. Educ., vol. 59, no. 2, pp. 81-90, 2016.

[2] R. Chibante, C. Vaz De Carvalho, and P. Ferreira, "A simulation tool to promote active learning of controlled rectifiers," Comput. Appl. Eng. Educ., no. November 2017, 2018.

[3] Z. Zhang, C. T. Hansen, and M. A. E. Andersen, "Teaching Power Electronics With a Design-Oriented, Project-Based Learning Method at the Technical University of Denmark," IEEE Trans. Educ., vol. 59, no. 1, pp. 32-38, 2016.

[4] D. G. Lamar, P. F. Miaja, M. Arias, A. Rodríguez, M. Rodríguez, A. Vázquez, M. M. Hernando, and J. Sebastián, "Experiences in the application of project-based learning in a switching-mode power supplies course," IEEE Trans. Educ., vol. 55, no. 1, pp. 69-77, 2012. 
[5] A. Córdova-Acosta, J. G. Calderón-Guizar, and O. G. Fragoso-Díaz, "An educational tool for introducing power engineering students with modal extraction concepts," Comput. Appl. Eng. Educ., vol. 11, no. 2017, pp. 4406-4413, 2018.

[6] S. Ayasun and C. O. Nwankpa, "Induction motor tests using matlab/simulink and their integration into undergraduate," IEEE Trans. Educ., vol. 48, no. 1, pp. 37-46, 2005.

[7] A. Yadav, D. Subedi, M. A. Lundeberg, and C. F. Bunting, "Problem-based learning: Influence on students' learning in an electrical engineering course," J. Eng. Educ., vol. 100, no. 2, pp. 253-280, 2011.

[8] A. Mantri, S. Dutt, J. P. Gupta, and M. Chitkara, "Design and evaluation of a PBL-based course in analog electronics," IEEE Trans. Educ., vol. 51, no. 4, pp. 432-438, 2008.

[9] S. Tan and Z. Shen, "Hybrid Problem-Based Learning in Digital Image Processing: A Case Study,” IEEE Trans. Educ., pp. 1-9, 2017.

[10] J. E. Mitchell, B. Canavan, and J. Smith, "Problem-Based Learning in Communication Systems: Student Perceptions and Achievement," Educ. IEEE Trans., vol. 53, no. 4, pp. 587-594, 2010.

[11] A. Kumar, S. Fernando, and R. C. Panicker, "Project-based learning in embedded systems education using an FPGA platform," IEEE Trans. Educ., vol. 56, no. 4, pp. 407-415, 2013.

[12] J. Kim, "An Ill-structured PBL-based microprocessor course without formal laboratory," IEEE Trans. Educ., vol. 55, no. 1, pp. 145-153, 2012.

[13] D. L. Maskell and P. J. Grabau, "A multidisciplinary cooperative problem-based learning approach to embedded systems design," IEEE Trans. Educ., vol. 41, no. 2, pp. 101-103, 1998.

[14] N. Hosseinzadeh and M. R. Hesamzadeh, "Application of Project-Based Learning (PBL) to the teaching of Electrical Power System ENgineering," Ieee Trans. Educ., vol. 55, no. 4, pp. 495-501, 2012.

[15] H. Hassan, C. Dominguez, J. M. Martinez, A. Perles, J. V. Capella, and J. Albaladejo, “A Multidisciplinary PBL Robot Control Project in Automation and Electronic Engineering," IEEE Trans. Educ., vol. 58, no. 3, pp. 167-172, 2015.

[16] S. Khan, M. H. Jaffery, A. Hanif, and M. R. Asif, "Teaching Tool for a Control Systems Laboratory Using a Quadrotor as a Plant in MATLAB," IEEE Trans. Educ., vol. 60, no. 4, pp. 249-256, 2017.

[17] M. T. Baldassarre, D. Caivano, G. Dimauro, E. Gentile, and G. Visaggio, "Cloud Computing for Education: A Systematic Mapping Study," IEEE Trans. Educ., pp. 1-11, 2018.

[18] B. Warin, O. Talbi, C. Kolski, and F. Hoogstoel, "Multi-Role Project (MRP): A New 
Project-Based Learning Method for STEM,” IEEE Trans. Educ., vol. 59, no. 2, pp. 137146, 2016.

[19] Z. Chen, W. Chen, X. Liu, and C. Song, "Development of an educational interactive hardware-in-the-loop missile guidance system simulator," Comput. Appl. Eng. Educ., vol. 26, no. 2, pp. 341-355, 2018.

[20] M. Marques, S. F. Ochoa, M. C. Bastarrica, and F. J. Gutierrez, "Enhancing the Student Learning Experience in Software Engineering Project Courses,” Ieee Trans. Educ., vol. 61, no. 1, pp. 63-73, 2018.

[21] J. R. Buck and K. E. Wage, "Active and cooperative learning in signal processing courses,” IEEE Signal Process. Mag., vol. 22, no. 2, pp. 76-81, 2005.

[22] C. R. Pryor and R. Kang, "Project-Based Learning," Comput. Educ., pp. 129-138, 2015.

[23] A. J. Swart, "Distance Learning Engineering Students Languish Under Project-Based Learning, But Thrive in Case Studies and Practical Workshops," IEEE Trans. Educ., vol. 59, no. 2, pp. 98-104, 2016.

[24] D. Gerónimo, J. Serrat, A. López, and R. Baldrich, "Traffic Sign Recognition for Computer Vision Project-Based Learning,” Ieeexplore.Ieee.Org, vol. 56, no. 3, pp. 364371, 2013.

[25] J. Alberto, N. Cocota, T. D. Angelo, P. Marcos, and D. B. Monteiro, "A Project-Based Learning Experience in the Teaching of Robotics," Ieee Rev. Iberoam. Tecnol. Del Aprendiz., vol. 10, no. 4, pp. 302-309, 2015.

[26] D. Callison, Setting the standard for Project Based Learning. 2006.

[27] I. Calvo, I. Cabanes, J. Quesada, and O. Barambones, "A Multidisciplinary PBL Approach for Teaching Industrial Informatics and Robotics in Engineering," IEEE Trans. Educ., vol. 61, no. 1, pp. 21-28, 2018. 